\title{
PENGARUH IBU BEKERJA TERHADAP PEMBERIAN ASI EKSKLUSIF PADA BAYI USIA 0-6 BULAN \\ (Di Rumah Sakit Islam Jemursari Surabaya Provinsi Jawa Timur)
}

\author{
Ratna Sari Dewi \\ STIKes Insan Cendekia Medika Jombang \\ Email: bidanratnasaridewi@yahoo.co.id
}

\begin{abstract}
ABSTRAK
Pemberian ASI di Indonesia belum sepenuhnya dilaksanakan. Upaya perbaikan perilaku menyusui, terutama ASI eksklusif masih kurang. Isu utamanya adalah faktor sosial budaya, kesadaran akan pentingnya ASI, pelayanan kesehatan dan tenaga kesehatan, promosi susu formula secara terus menerus dan ibu yang bekerja yang belum sepenuhnya mendukung Program Peningkatan ASI (PP ASI), disebabkan karena ibu yang bekerja tidak memberikan ASI penuh, mereka memberikan susu formula kepada 3 bayi yang menyusu secara ekslusif, dan 7 bayi yang tidak menyusu secara ekslusif. Tujuan penelitian ini adalah untuk mengetahui pengaruh ibu bekerja terhadap pemberian ASI eksklusif pada bayi usia 0 sampai 6 bulan di Rumah Sakit Islam Jemursari Surabaya Jawa Timur.

Desain penelitian ini adalah Analitik Cross Sectional. Populasinya ibu yang memiliki bayi usia 0-6 bulan yang berkunjung ke Rumah Sakit Islam Jemursari Surabaya Provinsi Jawa Timur 43 orang. Tehnik sampling menggunakan Consecutive Sampling dengan responden ibu bekerja 31 orang dan responden ibu tidak bekerja 9 orang sejumlah 40 orang. Instrumen penelitian menggunakan lembar observasi dengan pengolahan data editing, coding, tabulating dan uji statistik menggunakan Fisher Exact Test.

Hasil penelitian terhadap 4 responden $(12,9 \%)$ yang memberikan ASI eksklusif pada bayinya dari usia 0 hingga 6 bulan, sebesar $87,1 \%$ yaitu 27 responden yang tidak menyusui secara eksklusif pada bayinya dari usia 0 hingga 6 bulan dan responden yang tidak bekerja memberikan ASI eksklusif pada bayi usia 0-6 bulan sebanyak 7 atau sebesar $77,8 \%$ serta 2 responden yang tidak bekerja yaitu sebesar $22,2 \%$ tidak menyusui secara eksklusif pada bayinya usia 0-6 bulan. Hasil uji Fisher Exact Test menunjukkan nilai signifikansi $\rho=0,001<\alpha(0,05)$, sehingga $\mathrm{H}_{0}$ ditolak. Penelitian ini dapat disimpulkan bahwa ada pengaruh Ibu bekerja terhadap Pemberian ASI Eksklusif pada Bayi Usia 0-6 Bulan di Rumah Sakit Islam Jemursari Surabaya Provinsi Jawa Timur. Ibu lebih aktif untuk memberikan ASI Eksklusif pada bayi usia 0-6 bulan dengan cara bertanya kepada tenaga kesehatan, membaca buku, mengikuti penyuluhan manfaat ASI Eksklusif bagi ibu bekerja.
\end{abstract}

Kata kunci : Bayi Usia 0-6 Bulan, Ibu Bekerja, Pemberian ASI Eksklusif. 


\section{PENDAHULUAN}

Air Susu Ibu (ASI) adalah susu produksi manusia untuk dikonsumsi bayi dan merupakan sumber nutrisi utama bagi bayi yang tidak dapat mencerna makanan padat. ASI merupakan makanan alami dan pertama serta makanan terbaik bagi bayi alamiah, yang mengandung berbagai macam zat gizi yang diperlukan untuk proses tumbuh kembangnya (Roesli, 2012).

Berdasarkan WHO data ASI Eksklusif pada tahun 2005-2011 mengungkapkan bahwa $32 \%$ bayi Indonesia mendapatkan ASI Eksklusif dalam enam bulan pertama dan $50 \%$ anak menerima ASI Eksklusif hingga 23 bulan. Namun angka ini masih tergolong rendah dibandingkan negara berkembang lainnya. Berdasarkan hasil Survei Demografi dan Kesehatan Indonesia (SDKI) 2019, rentang pemberian ASI pada bayi usia 0 hingga 6 bulan masih jauh dari target yang ditargetkan sebesar 52,3\%. Menurut data Kabupaten / Kota, cakupan ASI eksklusif bayi di Jawa Timur tahun 2019 diketahui 64,08\%, dan menurut data Kota Surabaya tahun 2019 cakupan ASI Eksklusif pada bayi 0-6 bulan yaitu 60,52 \%. (Profil Kesehatan Jawa Timur, 2019)

Penelitian yang dilakukan oleh Nuryanto (2011) menemukan bahwa didapatkan hubungan yang signifikan antara pekerjaan ibu dengan menyusui secara penuh atau eksklusif, dan ibu yang bekerja 1,16 kali lebih tinggi memiliki risiko untuk berhenti menyusui sepenuhnya daripada ibu tidak bekerja. Marzuki (2011) menyatakan bahwa angka pemberian ASI secara eksklusif pada ibu tidak bekerja sebesar $(28,4 \%)$ lebih tinggi dibandingkan dengan ibu bekerja (20,0\%). Peneliti yang dilakukan oleh Andayni (2011) menemukan adanya hubungan antara pekerjaan ibu dengan pemberian ASI secara eksklusif yaitu sebesar (44\%), dan terdapat lebih banyak ibu tidak bekerja $(55,6 \%)$ dibandingkan ibu bekerja.

Berdasarkan hasil studi pendahuluan yang dilakukan pada tanggal 20 Juni 2020 dengan wawancara pada ibu yang memiliki bayi usia 0-6 bulan di Rumah Sakit Islam Jemursari Surabaya Provinsi Jawa Timur sejumlah 10 orang mendapatkan responden ibu bekerja 
7 orang dan responden ibu tidak bekerja 3 orang.

Terdapat banyak penyebab kegagalan pemberian ASI eksklusif, termasuk pekerjaan ibu. Meningkatnya partisipasi wanita dalam angkatan kerja, pembebasan segala bidang pekerjaan, dan kebutuhan masyarakat telah menurunkan kemauan untuk menyusui dan lamanya menyusui. Pekerjaan terkadang mengakibatkan keterlambatan dalam pemberian ASI eksklusif. Tegasnya, hal tersebut dikarenakan para ibu yang sibuk dan tidak memiliki cukup waktu untuk mengurus kebutuhan ASInya. Pada intinya, sebuah pekerjaan sebaiknya tidak menjadi alas an dan penyebab bagi ibu untuk menghentikan pemberian ASI secara eksklusif

Dalam upaya meningkatkan cakupan pemberian ASI Ekslusif maka perlu dilakukan kerjasama lintas sektor antara Dinas Tenaga Kerja dan Instansi tempat ibu bekerja dengan cara mendorong dan menganjurkan instansi yang mempekerjakan wanita sedang menyusui untuk mendirikan pojok laktasi dan memberikan keleluasaan penuh bagi ibu untuk menyusui bayinya. Bagi ibu bekerja agar tetap bisa memberikan ASI Eksklusif dan bisa dilakukan dengan cara diperah, dan disimpan di lemari es, selain itu penting untuk meningkatkan produksi ASI dan perawatan payudara. Cara yang lain yang bisa ditempuh ibu pulang kerumah saat kantor istirahat (jika rumah ibu dekat dengan tempat kerja), dan cara terakhir dengan menyusui bayi dipojok laktasi.

Berdasarkan latar belakang tersebut di atas, maka peneliti tertarik untuk meneliti Pengaruh Ibu Bekerja terhadap Pemberian ASI Eksklusif pada Bayi Usia 0-6 Bulan di Rumah Sakit Islam Jemursari Surabaya Provinsi Jawa Timur.

\section{METODE PENELITIAN}

Desain penelitian yang digunakan adalah Observasional Analitik dengan pendekatan Cross Sectional, yaitu suatu penelitian dimana melakukan observasi hanya satu kali saja dengan variabel independen (ibu bekerja) dan dependen (pemberian ASI Eksklusif pada bayi usia 0-6 bulan). Populasi yang berpartisipasi dalam penelitian 
ini berjumlah $40 \mathrm{ibu}$ yang bekerja di

Rumah Sakit Islam Jemusari Surabaya Propinsi Jawa Timur. Sampel dalam penelitian ini adalah ibu yang memiliki bayi usia 0 hingga 6 bulan di Rumah Sakit Islam Jemursari Surabaya Jawa Timur. Teknik pengambilan sampel menggunakan teknik non-probability sampling dan teknik continuous sampling untuk memilih sampel yang memenuhi kriteria penelitian selama periode waktu tertentu untuk memeriksa apakah jumlah sampel terpenuhi

Analisis data dalam penelitian ini menggunakan uji statistik ChiSquare dengan tingkat kemaknaan $\alpha=0,05 . \mathrm{H}_{0}$ ditolak jika $\mathrm{p}<\alpha$, asumsi Ada Pengaruh Ibu Bekerja Terhadap Pemberian ASI Eksklusif pada Bayi Usia 0 - 6 Bulan di Rumah Sakit Islam Jemursari Surabaya Provinsi Jawa Timur.

\section{HASIL DAN PEMBAHASAN}

1. Pekerjaan Ibu

Tabel 5.5 Distribusi Frekuensi Pekerjaan Ibu pada Bayi Usia 0-6 Bulan di Rumah

Sakit Islam Jemursari Surabaya Provinsi Jawa Timur Juni 2020.

\begin{tabular}{clcc}
\hline No & Pekerjaan Ibu & $\begin{array}{c}\text { Frekuensi } \\
\text { (f) }\end{array}$ & $\begin{array}{c}\text { Presentase } \\
(\%)\end{array}$ \\
\hline 1 & Bekerja & 31 & 77,5 \\
2 & Tidak bekerja & 9 & 22,5 \\
\hline & Total & 40 & 100 \\
\hline
\end{tabular}

(Sumber: Data Primer, 2020)

Berdasarkan tabel $\quad 5.5$ menunjukkan bahwa hampir seluruhnya ibu bekerja pada bayi usia 0-6 bulan, yaitu 31 responden $(77,5 \%)$.

\section{Pemberian ASI Eksklusif}

Tabel 5.6 Distribusi Frekuensi

Pemberian ASI

Eksklusif pada Bayi

Usia 0-6 Bulan di

Rumah Sakit Islam

Jemursari Surabaya

Provinsi Jawa Timur

Juni 2020.

\begin{tabular}{|c|c|c|c|}
\hline No & $\begin{array}{l}\text { Pemberian } \\
\text { ASI Ekslusif }\end{array}$ & $\begin{array}{l}\text { Frekuensi } \\
\text { (f) }\end{array}$ & $\begin{array}{c}\text { Presentase } \\
(\%)\end{array}$ \\
\hline 1 & Memberikan & 11 & 27,5 \\
\hline \multirow[t]{3}{*}{2} & Tidak & 29 & 72,5 \\
\hline & Memberikan & & \\
\hline & Total & 40 & 100 \\
\hline
\end{tabular}


Berdasarkan tabel $\quad 5.6$ menunjukkan bahwa sebagian besar pemberian ASI Eksklusif pada bayi usia 0-6 bulan, yaitu tidak memberikan sebanyak 29 (72,5\%).

3. Hubungan Pekerjaan Ibu terhadap Pemberian ASI Eksklusif pada Bayi Usia 0-6 Bulan

Tabel 5.7 Tabulasi Silang Hubungan antara Pekerjaan Ibu terhadap Pemberian ASI Eksklusif pada Bayi Usia 0-6 Bulan di Rumah Sakit Islam Jemursari Surabaya Provinsi Jawa Timur Juni 2020.

\begin{tabular}{lcccccc}
\hline \multirow{2}{*}{$\begin{array}{l}\text { Pekerjaan } \\
\text { Ibu }\end{array}$} & \multicolumn{3}{c}{$\begin{array}{c}\text { Temberian ASI Eksklusif } \\
\text { memberikan }\end{array}$} & \multicolumn{2}{c}{ an } & \\
\cline { 2 - 6 } & $\mathrm{f}$ & $\%$ & $\mathrm{f}$ & $\%$ & $\mathrm{f}$ & $\%$ \\
\cline { 2 - 6 } & 27 & 87,1 & 4 & 12,9 & 31 & 100 \\
Bekerja & 22,2 & 7 & 77,8 & 9 & 100 \\
Tidak & 2 & & & & & \\
bekerja & & & & & \\
\hline Total & 29 & 72,5 & 11 & 27,5 & 40 & 100 \\
\hline \multicolumn{4}{c}{ Uji Fisher's Exact Text $\rho=0,01$} & $\alpha=0,05$ \\
\hline
\end{tabular}

(Sumber : Data Primer, 2020)

Berdasarkan tabel 5.7 menunjukkan bahwa dari 31 responden pekerjaan, hampir semua ibu bekerja memberikan ASI nya secara Eksklusif yaitu sebesar 87,1\% atau 27. Sebanyak 7 responden atau sebesar $77,8 \%$ dari jumlah 9 responden yang tidak bekerja mereka secara eksklusif dalam memberikan ASI.

\section{PEMBAHASAN}

Hasil uji Chi-Square tidak memenuhi persyaratan karena nilai yang diharapkan kurang dari 5 atau sebesar 25\%, sehingga harus menggunakan Uji Fisher's Exact Test dimana hasil uji menunjukkan bahwa $\rho$ value $=001<\alpha=0,05, \mathrm{H}_{0}$ ditolak dan $\mathrm{H}_{1}$ diterima artinya Ada Pengaruh Ibu Bekerja terhadap Pemberian ASI Eksklusif pada Bayi Usia 0-6 Bulan di Rumah Sakit Islam Jemursari Surabaya Provinsi Jawa Timur.

Menurut Salfina 2012, terdapat beberapa sebab gagalnya pemberian ASI Eksklusif diantaranya pekerjaan ibu. Meningkatnya partisipasi wanita dalam angkatan kerja, pembebasan segala bidang pekerjaan, dan kebutuhan masyarakat telah menurunkan kemauan dalam menyusui dan lamanya menyusui. Pekerjaan terkadang mempengaruhi ibu sehingga terjadi keterlambatan 
dalam pemberian ASI eksklusif. Hal tersebut disebabkan oleh kesibukan ibu dalam bekerja sehingga ia tidak memperhatikan kebutuhan ASInya. Pada intinya, sebuah pekerjaan sebaiknya tidak menjadi alasan dan penyebab bagi ibu untuk menghentikan pemberian ASI secara eksklusif pada bayinya.

Menurut Roesli (2014), ASI Eksklusif merupakan hanya pemberian ASI tanpa penambahan cairan lain seperti susu formula, jeruk, madu, air teh, air untuk bayi, dan tidak ada makanan padat tambahan seperti pisang, pepaya, bubur susu, biskuit, bubur nasi, dan tim. Disarankan pemberian ASI eksklusif minimal selama 6 bulan, dan makanan padat mulai diberikan pada bayi setelah usia 6 bulan. Sedangkan ASI bisa diberikan sampai bayi berusia 2 atau lebih.

\section{KESIMPULAN DAN SARAN}

1. Ibu yang memiliki Bayi berusia 06 Bulan di Rumah Sakit Islam Jemursari Surabaya Provinsi Jawa Timur yaitu Hampir Seluruhnya Bekerja.

2. Pemberian ASI Eksklusif pada Bayi Usia 0-6 Bulan di Rumah Sakit Islam Jemursari Surabaya Provinsi Jawa Timur yaitu
Sebagian Besar Tidak diberikan ASI secara Eksklusif.

3. Ada Pengaruh pekerjaan ibu terhadap pemberian asi secara eksklusif pada Bayi Usia 0-6 Bulan di Rumah Sakit Islam Jemursari Surabaya Provinsi Jawa Timur.

\section{Saran}

1. Bagi Ibu Bekerja

Ibu lebih aktif dan bersedia untuk memberikan ASI Eksklusif pada bayi usia 0 hingga 6 bulan dengan bertanya pada tenaga kesehatan, membaca buku, mengikuti penyuluhan. Ibu dapat bertukar informasi tentang gizi yang baik bagi bayi usia 0-6 bulan dengan ibu lain yang memliki bayi usia 0-6 bulan, serta manfaat dan pentingnya ASI.

2. Bagi Institusi

Memperbanyak sumber pustaka yang dapat dijadikan sumber bacaan mahasiswa mengenai ASI Eksklusif pada bayi usia 0-6 bulan tanpa makanan tambahan.

3. Bagi Rumah Sakit

Berpartisipasi lebih aktif dalam memantau pemberian ASI eksklusif bagi ibu yang memiliki bayi usia 0 hingga 6 bulan, agar 
bidan menemukan solusi yang optimal dan memberikan edukasi mengenai gizi yang baik untuk bayi usia 0 sampai 6 bulan, serta manfaat dan pentingnya ASI. Tenaga kesehatan khususnya di Rumah Sakit juga menyediakan brosur atau leaflet mengenai manfaat ASI, pentingnya ASI, dan cara menyimpannya..

4. Bagi Peneliti Selanjutnya

Melakukan studi lebih lanjut terkait beberapa faktor yang dapat mempengaruhi pemberian ASI Eksklusif pada bayi dari usia 0 hingga 6 bulan seperti tingkat pengetahuan, dukungan keluarga, pekerjaan ibu, dan lain sebagainya

\section{DAFTAR PUSTAKA}

Afifah, (2012). Faktor yang Berperandalam Kegagalan Pemberian ASI Eksklusif. http:/magi.undip.ac.id/penelitian /31-versi-indonesia/83-faktoryang-berperan-dalam-kegagalanpraktik-pemberian-asi-eksklusif. (Diakses tanggal 29 Maret 2020)

Arifin, S, (2012). Sepuluh Langkah Untuk Keberhasilan Sukses Menyusui.http://rumahkusurgaku .wordpress.com/2020/03/29/sepu

luhsepuluh-langkah

untukkeberhasilanansuksesmenyusui/. (Diakses 29 Maret 2020)

Arikunto, S, (2011). Prosedur Penelitian Suatu Pendekatan Praktek. Jakarta, Bhineka Cipta.

Ayu, (2012). Konsep Dasar ASI Eksklusif. Jakarta: Salemba Empat.

Baskoro, (2012). Keperawatan Maternitas. Jakarta: EGC.

Baskoro, (2013). Keperawatan Maternitas. Jakarta : EGC.

Bobak, L. (2013). Keperawatan Maternitas. Jakarta: EGC.

Chunbley, (2012). Manajemen Laktasi, Jakarta. Bhineka Cipta.

Depdikbud, (2012). Definisi Pekerjaan, Profesi, Jabatan. Jakarta. Pusdikbud.

Depkes RI, (2011). Manajemen Laktasi, Jakarta. Pusdiknakes.

Depkes RI, (2012). Manajemen Laktasi, Jakarta. Pusdiknakes.

Hisabuan, (2012). Tuntutan Pekerjaan, Yogyakarta. Pustaka Pelajar. 
Hubertin, SP, (2011). Konsep Penerapan ASI Ekslusif. Buku Saku Untuk Bidan EGC, Jakarta $95 \mathrm{hlm}$.

Kasdu, (2011). ASI, Menyusui dan SADARI, Yogyakarta : Nuha Medika.

Mulyadi, (2011). Sistem Akutansi. Cetakan Keempat. Jakarta: Salemba empat.

Mubarok, (2011). Konsep dasar pengetahuan.

www.http://infomediakita.com/2010/ 04/html. (Diakses tanggal 20 April 2020)

Nursalam, (2014). Konsep dan Penanganan Metodologi Ilmu Keperawatan: Pedoman Skripsi, Tesis dan Instrumen Penelitian Keperawatan. Jakarta, Salemba Medika.

Notoatmodjo, S, (2012). Metode Penelitian Kesehatan, Jakarta, Bhineka Cipta.

Nursalam dan Pariani, (2011). Pendekatan Praktis Metodologi Riset Keperawatan. Jakarta: CV Sagung seto.

Purnomo Sigit, Ieda. (2013). Bahan Bacaan Manajemen Laktasi Edisi 2. Jakarta program manajemen laktasi perkumpulan perinatologi Indonesia.
Rachma Dewi, (2011). Pengetahuan, Sikap dan Praktek Pemberian ASI serta Status Gizi bagi Usia 4-12 Bulan di Pedesaan dan Perkotaan.

www.repository.iqb.ac.id

(Diakses tanggal 29 Maret 2020)

Roesli, Utami, (2012). Bayi Sehat Berkat ASI Ekslusif, Jakarta. Alex Media Komputindo.

Roesli, Utami, (2014). Bayi Sehat Berkat ASI Ekslusif, Jakarta. Alex Media Komputindo.

Rohani, (2013). Pengaruh Karakteristik Ibu Menyusui terhadap Pemberian ASI Eksklusif.

http://www.asioke.multiply.com. (Diakses tanggal 1 Juli 2020)

Sutam, (2013). Pemberian ASI Eksklusif Masih Rendah. http://asiku.wordpress.com/2013 /08/07/pemberian-asi-eksklusifmasih-rendah/. (Diakses tanggal 2 April 2020)

Sri, (2014). Faktor-Faktor yang mempengaruhi pemberian ASI Ekslusif. www.sri medicastore.com. (Diakses tanggal 2 April 2020)

Yuliarti, (2011). Pentingnya ASI Bagi Bayi. Jakarta: EGC. 